\title{
СЕМАНТИКА ПРАВДЫ И ЛЖИ В РУССКОЙ ФРАЗЕОЛОГИИ НА ФОНЕ ВЬЕТНАМСКОЙ ЛИНГВКУЛЬТУРЫ
}

\section{SEMANTICS OF TRUTH AND LIES IN RUSSIAN PHRASEOLOGY AGAINST THE BACKGROUND OF VIETNAMESE LINGUOCULTURE}

N. Nguyen

Summary: The article presents a comparative analysis of Russian and Vietnamese phraseological units with the semantics of restraint and intemperance of speech. Within the designated semantic group, the similarities and differences between the two linguistic cultures are revealed by analyzing the figurative basis of phraseological units. It is noted that the use of images of speech organs is common in the internal forms of the idioms of the two languages. However, the difference in the figurative bases of the phraseological units of these languages is found. At the same time, the axiological potential of phraseological images of restraint and intemperance of speech coincides.

Keywords: phraseological picture of the world, cultural linguistics, linguistic culture, speech activity.
И зучение культуры через призму языка является одной из характеристик современной науки. В связи с этим в настоящее время изучение национальных особенностей картины мира, идентифицирующих культуру, происходит через призму языковых явлений. В такой парадигме взаимосвязи языка и культуры фразеология представляет большой интерес, так как именно через устойчивые идиомы предаются краски национального восприятия мира. Лингвокультурологический подход к описанию семантики фразеологизмов представлен в работах В.Н. Телия, М.Л. Ковшовой, Н.Г. Брагиной, Красных В.В., Юриной Е.А. Макаровой Е.М. др.

Сопоставление идиом разных, особенно неродственных языков, представляет колоссальный интерес, так как только при сравнении можно выявить универсальные и национально идентифицирующие элементы той или иной лингвокультуры. Так выявлены особенности русского зыка на фоне китайской лингвкультуры в работах Казаковой Н.Н. и Лю С., немало работ сопоставляющих английские и русские фразеологизмы (Шенкал Г., Шерина Е.А. и др). Однако наименее изученной остаётся особенность русского языка на фоне вьетнамской лингвокультуры.

В статье посредством сравнительно-сопоставительного анализа фразеологизмов-идиом вьетнамского и
Нгуен Бик Нгок

Аспирант, Национальный Исследовательский Томский государственный университет nbnhanu@gmail.com

Аннотация: В данной статье представлен результат сопоставительного анализа русских и вьетнамских идиом с образным значением 'правда' и 'ложь'. В этой семантической группе фразеологизмов определены доминанты русской лингвокультуры, которые были выявлены при сравнении неродственных языков. Сопоставительный анализ показал, что аксиологические акценты в русском и вьетнамском языках совпадают, так как универсальны оценки правды как блага и лжи как зла. Однако в двух лингвокультурах эта диада передаётся через разные образные основания, которые более широко представлены в русском языке.

Ключевые слова: фразеология, образность, картина мира, лингвокультурология, лингвокультура, сопоставительный анализ.

русского языков с семантикой лживости / правдивости речи выявляются особенности русской картины мира, её аксиологические характеристики.

В качестве материала исследования использованы русские и вьетнамские фразеологизмы, представленные в следующих словарях: «Фразеологический словарь русского языка» под ред. А.И. Молоткова; «Большой фразеологический словарь русского языка. Значение. Употребление. Культурологический комментарий» под ред. В.Н. Телия; «Русская фразеология. Историко-этимологический словарь. Около 6000 фразеологизмов» под ред. В.М. Мокиенко; «Фразеологический словарь русского литературного языка» А.И. Федорова; «Thành ngũ tiếng Việt» Нгуен Лык; «Từ điển thành ngữ và tục ngữ Việt Nam» Нгуен Лан; «Từ điển giải thích thành ngữ tiếng Việt» Нгуен Ньы И, Нгуен Ван Ханг, Фан Суан Тхань.

Во всех языках мира присутствуют идиомы с семантикой характеристики речи, кроме этого, универсальна и диада правда - ложь, которая имеет особый аксиологический потенциал. Образная трансляция ценности правды и антиценности лжи, способствует выявлению общих и идентифицирующих черт русского и вьетнамского менталитета.

Результаты исследования, представленные в статье, 
демонстрируют фрагмент комплексного изучения фразеологического поля «речь» во вьетнамском и русском языках. Это поле, по данным фразеологических словарей, в русском языке насчитывается более 200 единиц, во вьетнамском - более 160 единицами.

В данной статье представлены результаты анализа нескольких групп фразеологизмов, включённых поле «речь», эксплицирующих семантику правдивости и ложности высказываний.

Понятия правды и лжи с одной стороны полярны, с другой - между этими полюсами расположена шкала степени правдивости речи, допустимости лжи, которая и демонстрирует аксиологические особенности лингвокультур.

\section{Прав $а$ а}

Абсолютная правда передаётся как через образные выражения, так и через безобразные. Например, называть (назвать) вещи своими именами 'говорить прямо, не скрывая ничего; честно говоря 'откровенно, как есть'; nравду сказать 'честно' это выражение подчёркивает достоверность сказанного.

В русском языке достаточно многочисленная группа фразеологизмов с компонентом слово 'информация, знание.' Например, честное слово в значении подтверждения информации, её правдивости; слово в слово 'совершено точно'; до слова о совершенно точном пересказе.

Ещё одно значение лексемы слово 'особая ценность, честь'. Эта семантика реализована в следующих образных выражениях: брать (взять, давать) слово 'получать (получить, давать) от кого-либо (кому-либо) обещание что-либо сделать' В таком понимании этой лексемы на слове можно поймать (ловить), то есть заставлять (заставить) кого-либо сделать то, о чём было сказано. Мы не раз ловили его на слове, когда он обещал...

Часто слово употребляется в значении 'право, возможность публичного выступления' Беру с тебя слово...

Другой образ, который передаёт значение правдивости, истинности - это твёрдость. Здесь символом образа становится неизменность формы. Такие выражения используются для подтверждения намерений, обещаний. То есть то, что обещано, будет выполнено, оно неизменно.

Для переносного значения твёрдости в значении 'истинность' использован образ олова как твёрдого материала. Например, слово - олово 'веско, неизменно'.

Образ твёрдости присутствует и во вьетнамской лингвокультуре. Например, в выражении nói như dao (rựa) chém đá/nói như dao (rựa) chém vào cột (chém xuống đất) (досл.: говорить так уверено, как будто ударить нож в камень) так говорят о сильном человеке, чьим словам доверяют.

Символьное значение неизменности во вьетнамском языке также может передаваться через образ заколачивания гвоздей, то есть действие, последствия которого нельзя изменить, если гвоздь заколочен, то его уже не вынуть. Поэтому сравнение с таким действием становится доказательством истинности сказанного. Например, như đính đóng cột (досл.: уверено говорить, как заколоченный гвоздь) 'говорить правду'

Схожий образ, передающий семантику истинности nрямота, то есть прямой - значит правильный, соответствующий истине и, напротив, непрямой - неистинный, в русском языке даже есть собственно образное слово кривда как антоним правда

Образ правды как чего-то прямого присутствует и во вьетнамском языке. Значение 'говорить правду, даже если обидно' передано в выражении ăn ngay nói thẳng (досл.: есть прямо, говорить прямо), в котором также процесс говорения ассоциируется с поглощением пищи.

Соматические метафоры, через которые передаются многие образные значения лексических единиц из поля речь, также транслируют семантику правдивости. Эти образные основания связаны с открытостью. Например, образы лицо и глаза использованы в выражениях говорить в лицо (в глаза) 'открыто, без утайки', то есть не отворачиваться, ничего не скрывать.

Ещё одна соматическая метафора голова становится компонентом фразеологизмов с общей семантикой 'правда'. В данном случае голова имеет значение чего-то жизненно важного, обеспечивающего существование, что ты как бы отдаёшь в залог того, что выполнишь обещание. Эта семантика реализована в выражении: головой отвечать 'уверение в точном выполнении обещанного'.

Во вьетнамском языке правдивость связана со знаниями, накопленным опытом, мудростью. То есть доверять словам можно только, если человек мудр, имеет доказательства из проверенных веками, уважаемых источников. Например, nói có sách mách có chưng (досл.: говорumь опираясь на книги, а показать с доказательством) 'говорить достоверно, иметь доказательства'.

Во вьетнамском языке правдивость может ассоциироваться со спокойствием, именно отсутствие тревоги является доказательством истинности слов. Вьетнамцы считают, что если человек ничего не скрывает, то ему не о чем беспокоится. Поэтому фразеологизм ăn bằng nói chắc со значением 'говорить правдиво, уверенно' дословно переводится как есть спокойно, говорить твёрдо. 
Как уже можно заметить многие метафоры речи во вьетнамском языке связаны с едой, поеданием. Поэтому неслучайно, что символьное значение'правда' передаётся через образ риса, то есть рис как настоящая ценность и правда - нечто драгоценное. К тому же есть рис - особый ритуал, уважаемый всеми и его нельзя нарушать так и нельзя нарушать правила общения, взаимоуважения нельзя лгать, так как лгать это тоже против правил. Например, ăn một đọi nói một lời (досл.: есть чашку риса, сказать одно слово), где рис - главная пища, и когда человек ест (еда некое достояние), он должен соблюдать правила, в том числе не лгать.

Интересный образ используется в пословице: nói toạc móng heo (досл.: говорит громко, чисто, не боятся как копыта свиньи) Образ копыт здесь возникает потому что на копытах нет волос, они гладкие, так и речь прямая без зацепок. Такое выражение используют в ситуации, когда человек оказался в неловком положении и высказал всё прямо; без обиняков, обмана. Эту идиому можно сравнить с русской резать правду в глаза 'высказать всю правду не боясь обидеть кого-то'.

Правдивость или ложность также оценивается также через метафору голос и степень правдивости выражается через интенсивность проявления голоса. Так в полный голос 'совершенная истина' и наоборот в полголоса 'что-то скрывая, недоговаривая'. Здесь скорее реализуется дихотомия полная информация и скрытая информация, а не правда и ложь.

Правду также ассоциируют с честью, связывают с сердцем и подчёркивают абсолют правды эпитетом чистая. Например, сказать по чести 'без прикрас, истина'; чистосердечно высказаться, от чистого сердца, сказать с чистым сердчем, высказаться от всего сердиа 'искренне, правдиво'. Таким образом, правда ассоциируется с чем-то очень важным, предстаёт как важная жизненно необходимая ценность.

Ещё одно значение правды, как необдуманного высказывания встречается и в русской и во вьетнамской идиоматике. Такая речь не характеризуется как истина, а скорее как случайное высказывание. Эти значения воплощаются через образы предметов и явлений, причиняющих боль, дискомфорт, или через метафоры грубого обращения.

Во вьетнамском языке можно выделить группу выражений с подобными значениями: ăn càn nói bậy (досл.: ecmь и говорить mo, чmo nonadaem) 'много говорит грубые слова, ругается'. Эта идиома используется для характеристики речи, высказанной человеком, когда он не отдаёт себе отчёт. Схожая семантика у выражения lời đầu lưỡi (досл.: слова на кончике языка) 'словам нельзя доверять, необдуманные'. Как показывают примеры, эти фразеологические единицы также связаны с процессом поглощения пищи и содержат соматические образы органов речи.

В русском языке значения необдуманных высказываний передаются через пространственные метафоры, такие как без дальних слов, сказать прямо, напрямую и пр.

Кроме этого, используются образы грубых действий: бросить или причинения боли: рубить, сгоряча, которые также могут сопровождаться соматическими метафорами, например, бросить в лицо (глаза) 'говорить (сказать) что-либо открыто, прямо'

В этом же значении используется образное слово правда-матка 'правда без прикрас', здесь подчёркивается важность правды как начала жизни, однако слово имеет коннотацию грубости, что указывает на то, что высказывания, которые называют правдой-маткой не всегда приятны и их не всегда уместно произносить. В идиоме правду-матку резать особенно подчёркивается неприятность такой речи, способность приносить дискомфорт этими словами.

Если представить себе пространство между полюсами правды и лжи, то межу ними будет неточность, неопределённость, так как это и не абсолютная ложь, но и не правда. Образные выражения со значением неопределённости встречаются как в русском, так и во вьетнамском языках. Например, ăn ốc nói mò (досл.: eсть улитки, говорить догадками) 'говорить загадочно' так говорят, потому что улиток очень трудно найти, их нужно нащупывать под землёй, в траве, на их поиски приходится тратить много времени, так и на поиски истины в высказывании нужно время. Метафоры пространства реализованы в идиоме nói ngược nói xuôi (досл.: говорить назад, говорить вперёд), то есть говорить то одно, то другое, что из этого правда не понятно.

В русском языке значение неопределённости может передаваться и через безобразные выражения, например, ни да, ни нет не говорит 'не может сказать чтолибо определённое' или через образы загадки, тумана, вуали, как например, в выражениях: говорить загадками, туманные речи, высказываться завуалированно.

\section{ヘожь}

Ложь в обеих лингвокультурах предстаёт как абсолютное зло, мешающее или даже уничтожающее жизнь. Поэтому, например, во вьетнамском языке она связна с метафорой кровь: ngậm máu phun người (досл.: набрать кровь во рту и хлынул во человек) 'ложь, которая может привести к смерти', здесь речь идёт о наговоре, когда лживая информация о ком-то может навредить 
человеку. Подобное значение содержится и в идиомах: vu oan giá họa/ vu oan giáng họa (досл.: упрекнуть человека, принося ему беду); ăn không nói có (досл.: есть не говорит да) 'чего-то не было, а сказать, что было'

Как уже упоминалось выше, во вьетнамской лингвокультуре говорение переосмысляется через процесс поглощения пищи или соматические метафоры. Такое ассоциативное сближение связано с пониманием говорения как процесса проходящего через рот. Слова и еда проходят через рот, поэтому и семантика лжи передаётся соматическими метафорами органов речи. Эти метафоры нередко могут сопровождаться эпитетами грязный, нечистый, то есть ложь ассоциируется с чем-то что портит, делает неприятным, непригодным.

Например, ăn gian nói dối (бдосл.: кушать нечисто) 'жульничать и лгать' или lưỡi không xương(nhiều đường lắt léo) (досл.: язык без костей на всякие извилистые повороты способен) 'способность лгать', так говорят о лживом человеке, и о его характере; ăn đơm nói đặt /Nói đơm nói đặt (досл.: есть лишнеe) 'наговаривать, возводить напраслину, преувеличивать'.

В русском языке навет, неправда передаются более разнообразной палитрой образов. Так, к примеру, зооним собака является компонентом фразеологизма со значением необоснованного обвинения: вешать (навешать) собак (на шею) 'наговаривать (наговорить) на кого-либо, необоснованно обвинять (обвинить) в чёмлибо'. Кулинарная метафора лапша, также присутствует в фразеологизме со значением ложь: вешать лапшу на уши 'говорить неправду'.

Значение 'сплетничать, злословить о ком-либо' передаётся через образ костей, в выражении косточки перемывать, то есть когда сплетничают, то как бы разбирают по частям человека, по костям и не просто моют, а перемывают, делают тщательно на несколько раз, чтобы ничего не упустить из виду.

Ложь также может пониматься как преувеличение. Во вьетнамском языке эта семантика опять же передаётся через метафоры поглощения пищи: ăn hơn, nói kém (досл.: есть больше, а говорить меньше) или ӑn thừa nói thiếu (досл.: есть лишнеe, а говорить меньше) 'говорит неправду о чем-то, преувеличивает'.

Семантика лжи, сообщения неправды в русском языке передаётся через образ небрежного обращения со словом, например, посредством идиом: бросать (бросить) слова на ветер 'говорить (сказать) впустую; опрометчиво обещать (пообещать) и не выполнять (выполнить) обещанного'. Здесь ложь ассоциируется с ничем не закреплённым словом, то есть то, что сказано улетучилось, улетело с ветром и его больше нет.

Бросаться словами 'безответственно говорить, обещать что-либо, не будучи уверенным в выполнении своего обещания'.

Пространственные метафоры также передают лживость, несоответствие реальности, неоправданных обещаний: семь вёрст до небес 'наобещать, наговорить очень много'. И во вьетнамском языке thề non hẹn biển (досл.: обещает до горы, обещать до моря 'дать обещание, которое знаешь, что не сдержишь так говорят обещании человека'

Интересные образы не присущие русской лингвокультуре реализованы о вьетнамских идиомах: thề sống thề chết (досл.: обещать жизнью, обещать смертью) 'дать честное слово, но не быть уверенным'; thề cá trê chui ống (досл.: обещать не обещать, но щука пролезет через трубу) 'напрасные обещания'.

Не прямая ложь, а скорее сокрытие правды передаётся через соматические образы зубов в идиоме зубы заговаривает в значении 'говорит не то, что нужно, важно'.

Во вьетнамском языке сокрытие правды тоже может быть ассоциативно связано с соматическими образами: há miệng mắc quai (досл.: не может открыть рот, боится раскрыть своч ошибки), то есть скрывать правду, бояться заговорить, чтобы случайно не выдать какие-то секреты, что-то нехорошее или чтобы что-то не пообещать.

Но ложь не всегда зло, она может быть и безобидной или помочь в трудной ситуации. Семантика такой безобидной лжи передаётся во вьетнамской культуре через фольклорный образ Куоя, молодого находчивого и хитрого парня. Это скорее положительный герой, его ложь никому не приносила вреда. Например, nói dối như сиội (досл.: врет как куой) 'говорить пустяки, что-то незначительное'. В русском языке есть схожее по значению выражение нести чушь 'говорить о чём-то неважном, нереальном'

Таким образом, в русской и вьетнамской лингвокультурах диада правда - ложь предстаёт в основном через соматические и пространственные образы. Правда оценивается как нечто ценное, чистое, жизненно необходимое и, наоборот, ложь является злом, разрушающим жизнь. Это схожесть в акциологических доминантах свидетельствует об универсальности этих метафор. Отличительная черта русской лингвокультуры в большем разнообразии образных переносов и количестве фразеологических единиц, передающих семантику правдивости или лживости речи. 
ЛИТЕРАТУРА

1. Телия, В.Н. Русская фразеология. Семантический, прагматический и лингвокультурологический аспекты / В.Н. Телия. - М., 1996. - 288 с.

2. Ковшова М.Л. Опыт семантического поля в описании идиома // Фразеология в Машинном фонде русского языка. Сб. статей / отв. ред. В.Н. Телия. М., 1990. - C. 80-88

3. Брагина Н.Г. Фрагмент лингвокультурологического лексикона (базовые понятия) // Фразеология в контексте культуры./ Н.Г. Брагина - М., 1999. C. $131-138$

4. Красных В.В. Этнопсихолингвистика и лингвокультурология: Курс лекций / В.В. Красных. - М. : ИТДГК“Гнозис", 2002. - 284

5. Юрина Е.А. Словарь русской пищевой метафоры. Т. 1: Блюда и продукты питания. Томск: Изд-во Томского университета, $2015 .$.

6. Маркова Е.М. Метафорическое развитие славянских названий ландшафта. Вестник ННгу. 2013, №6-2: С. 150-153.

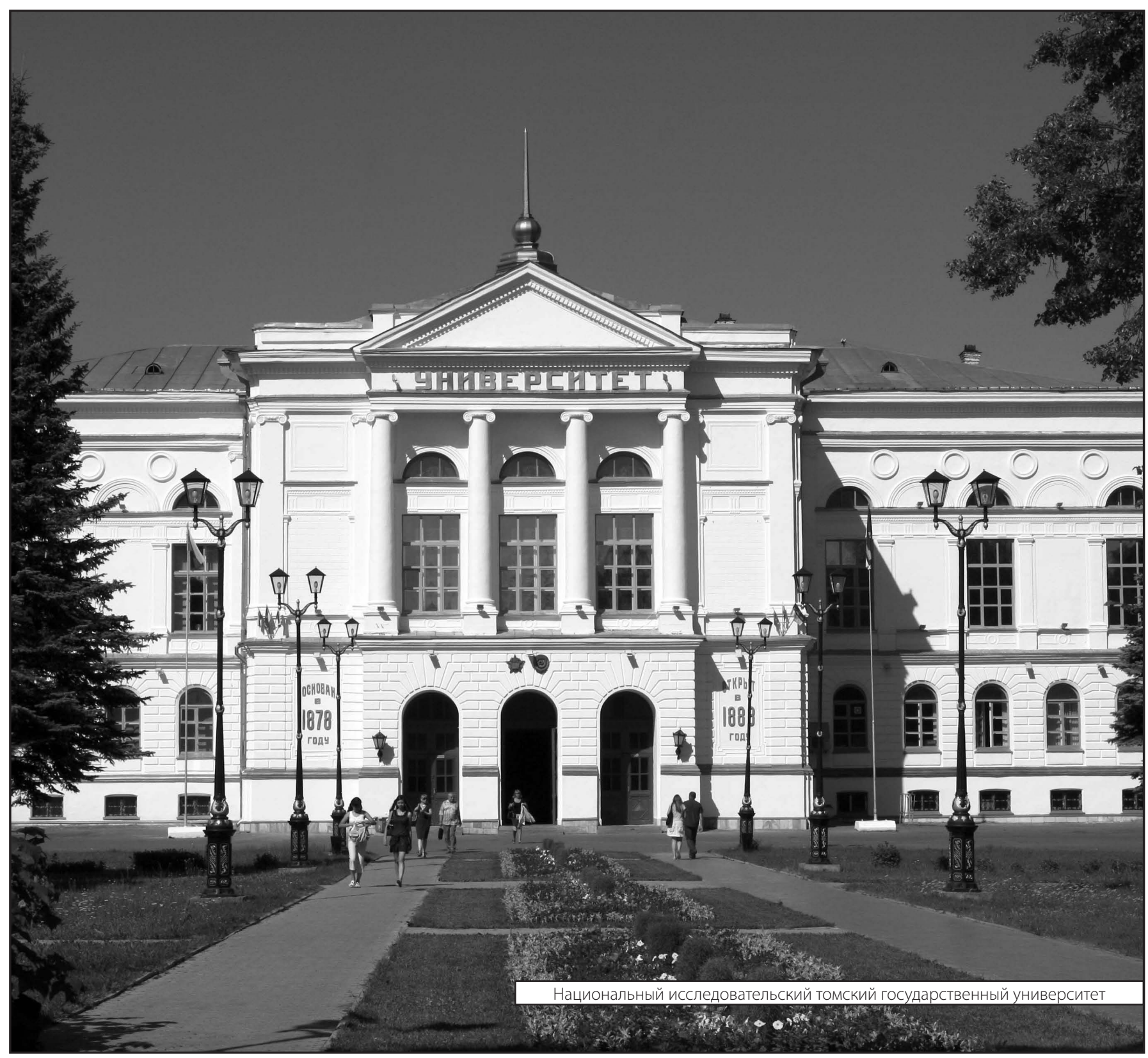

